\title{
Os sentidos de alfabetizar na pré-escola: algumas reflexões
}

\author{
Cleonice Maria Tomazzetti* \\ Daliana Loffler**
}

\section{Resumo}

Este texto é resultado de análise de dados produzidos em trabalhos circunscritos ao nível pré-escolar, desenvolvidos com duas professoras em momentos e contextos distintos. As fontes de produção e análise dos dados para esse texto foram obtidos, principalmente, dos registros da prática de estágio supervisionado na Educação Infantil e durante pesquisa de mestrado em educaçáo. A partir desses registros propóem-se algumas reflexóes acerca do processo de apropriação da língua escrita por crianças em idade pré-escolar e são explorados aspectos da infância institucionalizada, a criação, a participação e a geração de novos potenciais que se entrecruzam com dimensôes propostas nas açóes docentes, como de controle e repetição. Questionamse os sentidos das práticas "alfabetizadoras" em contraponto à leitura de mundo com crianças que fazem, sonham e vivem a potência da existência humana. Tais reflexóes sobre os sentidos de alfabetizar na pré-escola são desenvolvidas à luz das Diretrizes Curriculares Nacionais para a Educação Infantil e de referenciais próprios da área da alfabetização. As discussôes apresentadas no presente texto consideram que a complexidade da infância permite compreender as crianças em imersão no universo da leitura e da escrita muito antes de frequentarem as escolas, encarando este momento como náo exclusivo do início da vida escolar das crianças. Este processo pode ser encarado como uma iniciaçáo ou acontecimento, em que as crianças também aprendem a ler e a escrever descobrindo os caminhos sem deixar de ser criança, visto que elas não aguardam, necessariamente, a escola para iniciarem essas aprendizagens.

Palavras-chave: Alfabetização. Letramento. Educação pré-escolar.

\footnotetext{
* Doutora em Educaçáo pela Universidade Federal de Santa Catarina (UFSC). Professora da Universidade Federal de Santa Maria (UFSM) e da Universidade Federal de São Carlos (UFSCar) ** Mestre e Doutoranda em Educaçáo pela Universidade Federal de Santa Maria (UFSM).
} 
Este texto teve sua origem em dados de fontes e contextos distintos de pesquisa, produção e análise, realizados pelo Grupo de Investigação e Estudos Contemporâneos em Educação da Universidade Federal de Santa Maria (GIECEI/UFSM). Estão circunscritos ao trabalho desenvolvido por duas professoras de pré-escola: uma atua na perspectiva da "pré-alfabetização" em uma classe de crianças com cinco e seis anos na zona urbana ${ }^{1}$; a outra, na classe de quatro e cinco anos em um contexto de zona rural ${ }^{2}$.

A proposta é refletir acerca de algumas práticas vivenciadas por préescolares e suas professoras no processo de apropriaçáo da língua escrita e, no seu decorrer, explorar dimensóes da infância institucionalizada em relaçáo às interaçōes, às práticas sociais e às práticas escolares da leitura e da escrita. A partir de então, questionamos os sentidos das ações "alfabetizadoras" na educação infantil, não como um contraponto aos processos do letramento, mas às práticas educativas que náo colaboram para a construçáo de significaçóes sobre a escrita considerando suas diferentes práticas sociais na creche ou na pré-escola. Tais reflexóes sobre os sentidos de alfabetizar na pré-escola são desenvolvidas à luz das Diretrizes Curriculares Nacionais para a Educação Infantil (BRASIL, 2009b), dos referenciais teóricos sustentados em pedagogias participativas (KISHIMOTO; OLIVEIRA-FORMOSINHO, 2013; FARIA; MELLO, 2009), e de referenciais próprios da área da alfabetização como Soares (2003). Buscaremos nos posicionar no debate para discutir acerca dos sentidos que as vivências na cultura da escrita podem adquirir para a aquisiçáo do código escrito e dos usos sociais que deles fazemos nos contextos institucionalizados da infância.

Vivemos em um momento particularmente in-tenso nesse debate, pois as novas Diretrizes Curriculares Nacionais da Educação Infantil foram instituídas através da Resolução n5, em 17 de dezembro de 2009 (BRASIL, 2009b), e, passados cinco anos, ainda presenciamos discursos e práticas pedagógicas que não conseguem superar a falsa dicotomia entre os termos alfabetização e letramento, nem mesmo abandonar as orientaçóes curriculares anteriores, instituídas pelos Referenciais Curriculares Nacionais para a Educação Infantil (RCNEI) (BRASIL, 1998), que preconizavam um trabalho muito sistemático em todas as áreas do conhecimento, inclusive na aquisição do sistema alfabético ${ }^{3}$. Concordamos que há pouco consenso, que não existem definições capazes de agradar a todas as correntes de pensamento presentes nas pesquisas na área. E, quando o consenso sobre o conceito se apresenta, vem cercado por um contexto 
ideológico que importa, sobretudo, aos que se preocupam com a avaliação da alfabetização, com a medição dos níveis de letramento de uma população (SOARES, 1998).

A educação infantil, todavia, tem outros propósitos e, como afirma Maria Carmen Silveira Barbosa (2009), para evitar o risco de que ela seja uma simplificação da escola dos anos iniciais, não é demais afirmarmos as funçôes para os estabelecimentos que atendem bebês, crianças pequenininhas e crianças pré-escolares. A primeira é sua função social, que consiste em acolher, para educar e cuidar, compartilhando com as famílias o processo de formação e constituição da criança pequena em sua integralidade. A segunda é política, cuja função é contribuir para que os "pequenos" usufruam de seus direitos sociais e políticos e exerçam seu direito de participação, tendo em vista a sua formaçáo na cidadania. Por fim, a terceira função é a pedagógica por ser este um lugar privilegiado de convivência e ampliaçáo de saberes e conhecimentos de diferentes naturezas entre crianças e adultos (BARBOSA, 2009).

Nessa perspectiva, nossa reflexão buscará contribuir para a diferenciação entre as dimensões política e pedagógica da vivência da língua escrita nas creches e pré-escolas enquanto experiência significativa com as manifestaçôes escritas de sua própria língua, bem como refletir sobre as açóes exclusivamente escolares, as quais se fundamentam no uso de antigos métodos de alfabetização baseados em práticas transmissivas (OLIVEIRA-FORMOSINHO, 2009), em exercícios repetitivos de coordenação motora e outros destinados à prontidão para a escrita mecânica que, por sua vez, afastam as crianças das práticas sociais e da escrita como expressão, experiência humana e comunicação.

\section{Contextos que educam crianças pequenas ${ }^{4}$}

Nosso trabalho desenvolve-se a partir da realidade do município de Santa Maria, uma cidade de porte médio ${ }^{5}$, situada na regiáo central do Estado do Rio Grande do Sul, com um sistema considerado razoável para o atendimento educacional às crianças entre zero e cinco anos de idade, realizado principalmente no sistema de Escolas Municipais de Educação Infantil (EMEI) e nas classes de pré-escola alocadas em Escolas Municipais de Ensino Fundamental (EMEF) e/ ou de Educação Básica do sistema municipal ou do sistema estadual de educação pública, coordenadas pedagógica e politicamente pela Secretaria de Município da Educação e pela $8^{a}$ Coordenadoria Regional de Educação, respectivamente. 
Atualmente, o município mantem vinte e quatro (24) EMEI, sendo uma na zona rural, localizada no distrito de "Boca do Monte", e as demais nos bairros da periferia urbana da cidade. As EMEI e as EMEF da cidade recebem crianças oriundas de uma população de trabalhadores assalariados, ligados a empregos de baixa remuneração e que possuem uma reduzida escolaridade como, por exemplo, empregadas/os domésticas/os, catadores e recicladores, atendentes de estabelecimentos comerciais, pessoas com subemprego ou empregos temporários, e inclusive um considerável índice de desempregados. Além dessa configuração, essas escolas também recebem crianças de famílias empresárias e comerciantes de micro e pequeno porte, e de funcionários públicos de nível socioeconômico e educacional médio (servidores militares e civis e da burocracia municipal).

Já a escolas da rede estadual de ensino, localizam-se mais próximas ao centro da cidade ou em bairros de classe média e alta, atendendo a uma população de crianças a partir de quatro (04) anos e jovens cujos pais têm empregos públicos de melhor remuneraçáo, ou são empresários/profissionais liberais com mais recursos econômicos e educacionais. De um modo geral, as escolas que não são exclusivas de Educação Infantil (EMEF ou escolas da rede estadual) têm em comum a produção de espaços iguais para crianças pequenas e para crianças e jovens do Ensino Fundamental e Médio.

O quadro 1 expressa o número de escolas/classes que atendem as crianças na faixa etária de zero a cinco anos de idade e as respectivas matrículas no município.

Quadro 1 - Demonstrativo do número de escolas e matrículas de zero a cinco anos de idade

\begin{tabular}{|l|c|c|}
\hline & No de escolas & Matrículas \\
\hline $\begin{array}{l}\text { Municipais (EMEI/ } \\
\text { EMEF) }\end{array}$ & 46 & 2.381 \\
\hline Estaduais & 3 & 67 \\
\hline Federais & 1 & 74 \\
\hline Total & 50 & 2.522 \\
\hline \multicolumn{2}{|c|}{ População aproximada de 0 a 5 anos de idade: 19.063} \\
\hline
\end{tabular}

Fonte: Flôres, 2014. 
Eis o contexto no qual se insere este trabalho, o qual pretende discutir e analisar a natureza das atividades desenvolvidas, como já foi dito, por duas professoras de educação infantil, uma que atua na pré-escola de uma EMEF, e outra que atua em uma turma de pré-escola de EMEI, na zona rural da cidade. Ambas possuem formação específica para trabalhar com a Educação Infantil: a primeira, em Pedagogia para a Educação Pré-escolar, atuando também na antiga $1^{a}$ série dos Anos Iniciais, e a segunda formada em Pedagogia-Educação Infantil e matérias pedagógicas para o antigo segundo grau, sendo também professora de Berçário I em uma EMEI em outro bairro da cidade, além de já ter exercido a docência no $\mathbf{1}^{\mathbf{o}}$ ano do Ensino Fundamental logo que se iniciou o Ensino Fundamental de Nove Anos.

Os entendimentos e as práticas didático-pedagógicas relacionadas à alfabetização e ao letramento na pré-escola não são orientados por uma única abordagem ou tendência; entretanto, apresentam elementos comuns: o "medo" de estar errando, ou de ser acusados de não fazer nada pela "preparação" para o primeiro ano; o esforço para ensinar o alfabeto e as famílias silábicas mais simples como se a representaçấo alfabética pudesse ser vista como um sistema de codificação; a presença do alfabeto estendido em um lugar de destaque na sala bem diante das crianças. Assim, é que dizemos que existe - em termos de alfabetização - uma tendência padronizada entre as escolas infantis, sejam elas da zona rural, EMEI ou classes pré-escolares em escolas municipais de ensino fundamental (EMEF).

\section{O que fazer se já estão pré-alfabetizados?}

A classe pré-escolar considerada nessa reflexão está situada em uma EMEF da zona leste do município, em um dos bairros periféricos com uma infraestrutura relativamente básica (ruas calçadas e iluminadas, escola, coleta de lixo, rede de esgoto em instalação, Unidade de Saúde próxima), mas o bairro não dispóe de vagas em creche e pré-escola em número suficiente, por isso, ainda existem muitas classes pré-escolares funcionando junto às EMEF em todos os bairros da cidade. A turma em questão ocupa uma sala cujas dimensóes são um pouco maiores que as das crianças dos Anos Iniciais, porém com o mesmo projeto: janelas altas, pouca iluminação natural e com mobiliário semelhante ou igual ao dessa etapa da Educaçáo Básica: composto de carteiras e cadeiras grandes e quadros negros ao alcance dos adultos, dentre outras deficiências. 
Ao iniciar o ano letivo, a professora, que acolheu as crianças na turma do Pré no turno da manhã da EMEF, realizou uma "investigação" sobre o que as crianças já sabiam para decidir de que ponto partiria na elaboração de sua programação: incentivou a produção gráfica de forma livre; permitiu a exploração de diferentes recursos para desenho e pintura com o giz de cera, lápis de cor ou cantas hidrográficas; permitiu a livre circulação das crianças pela sala para organizarem brincadeiras e comporem cenários com os objetos e materiais disponíveis na sala; explorou diferentes tipos de literatura infantil e outros suportes de texto em diferentes momentos do período, como em brincadeiras de faz de conta, escritas coletivas de cartazes e bilhetes, roda de leitura ou exploração individual de livros, revistas e jornais.

Nessa perspectiva teórico-metodológica, consideramos que o planejamento realizado foi embasado em suas observaçóes a respeito dos conhecimentos prévios das crianças e dos elementos que elas já conhecem. A docente, ao estabelecer vários momentos de interaçáo entre as crianças, e destas consigo, cria espaços para que as relaçóes sejam mais horizontais e menos hierárquicas, mais participativas e menos formalistas, e as crianças têm, assim, oportunidades de informar, nas conversas com a professora ou entre si, suas vivências e expectativas a respeito da escrita, das práticas de leitura nos seus distintos grupos familiares/sociais. Além disso, a professora também acatou sugestôes da coordenadora pedagógica da escola para compor seu planejamento, a qual recorreu em busca de orientaçóes. Mas ainda assim, em certo sentido, esse é um plano individual e solitário, visto que não há sequência de seu desenvolvimento e o compartilhamento de suas propostas com as crianças, bem como suas intençóes e/ou ideias também não são partilhadas com outros docentes da escola, como a responsável pela pré-escola do turno da tarde ou as colegas dos anos iniciais. Também é possível depreender da fala da própria professora que ela não avança nas práticas sociais da escrita e da leitura, sobretudo porque náo parte daquelas primeiras observaçóes a respeito do que as crianças já sabem, e de como a escrita está presente em suas vidas.

Identificamos que sua preocupação inicial com o diagnóstico está circunscrita a uma "medição" dos níveis de alfabetização e letramento das crianças para nivelar o trabalho a ser feito com o grupo. Demonstra desconhecer o potencial das falas e manifestaçôes ativas das crianças, pois quando afirma que " $O$ planejamento é eu comigo mesma [...]", interrompe o fluxo de possibilidades que a participação das crianças pode trazer ao planejamento mais articulado às realidades e aos usos e funçóes que esses sujeitos fazem da língua escrita em situaçóes sociais. 
Ao iniciar o ano letivo, essa professora identificou que muitos elementos comuns a estágios iniciais da alfabetização (por ela nomeados de préalfabetização) já haviam sido adquiridos pelas crianças que frequentaram, no ano anterior, o Jardim A na própria escola, sendo que na época, a maioria delas tinha idades entre quatro e cinco anos. Isso a inquietou por dois motivos: qual trabalho ela teria de propor a essas crianças, já que a maioria delas já dominava - na prática - o reconhecimento das letras do alfabeto, a escrita dos numerais, assim como o manuseio do caderno, a produçáo de tarefa de casa, por exemplo? E, como ela organizaria suas atividades com as crianças que ingressaram novas na turma (oito de um total de 20), e que, portanto, náo compartilhavam das mesmas vivências, não tinham a mesma experiência escolar que a maioria dos alunos?

Considerando que essa pré-escola funciona anexa à unidade de ensino fundamental de uma periferia urbana da cidade, não é de se estranhar que, até aquele momento, um número alto de crianças nunca tenha frequentado a educação infantil e estava entrando pela primeira vez em uma escola. Também sabemos que as expectativas do corpo docente dos anos iniciais exercem, de certo modo, uma pressáo sobre o trabalho pedagógico e sobre a professora e as crianças da classe de pré-escola. Afinal, a pré-escola é minoria neste contexto.

As atividades nessa classe passaram então a ser encaradas como um desafio, pois para a professora, até a "simples" tarefa diária de preencher o calendário tornou-se um problema: enquanto um número significativo de crianças vinha de uma turma de jardim A (ano anterior) e apresentavam destreza com objetos e rotinas da escola, as outras crianças que chegavam agora iniciavam a sua vida escolar depois das outras. Nesta prática pré-escolar, normalmente o calendário é preenchido diariamente e individualmente pelas crianças, em uma folha A4 composta por 30 ou 31 quadrinhos, onde elas colocam o numeral correspondente ao dia do mês no canto superior esquerdo de cada quadrinho e desenham algo que se identifica com o tempo/clima do dia conforme a observaçáo feita pela janela da sala de aula. Também é feita a escrita do próprio nome em cada trabalho realizado, assim como já é incentivada a utilização do caderno pautado para a reproduçáo de bilhetes para os pais ou a transcrição de ordens escritas das tarefas de casa.

A essas tarefas rotineiras a professora nomeou como pré-alfabetizadoras, uma vez que, segundo seu entendimento, são adequadas para o contexto préescolar, fazendo uma comparaçáo com tal período e o primeiro ano - este sim, 
responsável pela alfabetização propriamente dita. Assim, por que não pensou em mudar as tarefas?

Pensamos que seja porque essa perspectiva que se preocupa como as crianças reconhecem as letras pela memória visual ou sonora, se elas conseguem grafar corretamente as letras e sabem a sequência da escrita de seu nome desconhece as questóes enfrentadas pelas crianças mostradas pelos estudos sobre a psicogênese da língua escrita (FERREIRO; TEBEROSKY, 1985). Essas questôes não são apenas relativas à transcrição dos sons, de memorização de letras, de percepção sonora das palavras ou de técnicas de grafia, são, sobretudo, de ordem conceitual.

Ao pensar em atividades "pré-alfabetizadoras" para as crianças da préescola, havia a preocupação da professora em não antecipar a alfabetização; queria preservar o trabalho da pré-escola como de pré-alfabetização, resguardando-se do trabalho da alfabetização que, por sua vez, é prerrogativa das professoras dos primeiros anos do ensino fundamental.

Todavia, naquele momento, evidenciou desconhecer que é fundamental saber que para as crianças se apropriarem do nosso sistema de escrita, elas precisam compreender seu processo de construção e suas regras de produção, mais do que apresentar tarefas voltadas à mecânica da escrita (VIGOTSKI, 1994). A não compreensão desse ponto causa os mais terríveis equívocos do ensino na educação infantil.

\section{Mas eu não consigo...}

A Escola Municipal de Educação Infantil "Boca do Monte" é a nossa segunda escola considerada no texto, e atende a crianças moradoras da localidade rural de mesmo nome, cujas famílias são de pequenos e grandes proprietários rurais e de trabalhadores assalariados dessas propriedades e de estabelecimentos de pequeno comércio. Para chegar até a escola, que é de turno integral, as crianças utilizam o transporte escolar ou são levadas pelos seus familiares, desfrutando de um agradável passeio entre árvores e paisagens rurais.

Da estrada é possível avistar a escola colorida de madeira, rodeada por um lindo gramado; a pracinha das crianças é grande, com três grandes árvores que as acolhem à sombra. À medida que o cenário rural é tomado pela proximidade do prédio escolar, percebe-se que embaixo das sombras quase não há brinquedos para as crianças; há alguns potes plásticos de tamanhos diversos, 
colheres, brinquedos quebrados, alguns pneus e areia. $\mathrm{O}$ colorido da escola dá a impressão de que sua construção é de um perfeito acabamento, quando, na verdade, por baixo das tintas, esconde-se uma construção precária e muito antiga de madeira, com mais de 50 anos.

Em um dos dias de observação, as crianças da pré-escola faziam uma atividade de pintura na sala, e uma das crianças tinha em suas mãos uma ficha verde (durante todas as atividades de produção de trabalhos em folhas de ofício A4, as crianças recebiam essas fichas com o seu nome escrito para ser copiado em cada trabalho). Uma das crianças hesita entre brincar de telefone com a tampa do pote dos lápis de cor, e deter-se em copiar o seu nome no trabalho. Ela ainda não tinha dado seu trabalho por encerrado. Enquanto a professora a observa, a criança parece estabelecer diálogos e gesticular ao "telefone"; um coleguinha ao lado diz: "Profe, eu não consigo fazer; Prooofe?!!". A professora retira-se, levando consigo alguns materiais nos braços (trabalhos das crianças em folhas de ofício A4 e lápis de cor).

Ao observarmos a turma por um ângulo mais amplo, percebemos que a criança que estava "ao telefone" é a única que permanece com a atividade do desenho e a ficha para copiar o nome, enquanto os outros colegas já são organizados para outra tarefa. Alguns segundos depois, a professora solicita que os materiais sejam todos guardados, e uma das meninas retira os lápis de cor de perto da criança, enquanto a professora aproxima-se dela retirando também sua folha e escrevendo ela mesma o nome do menino no trabalho. As imagens 1, 2 e 3, extraídas da pesquisa de Löffler (2012), ilustram essa situação.

\section{Imagem 1 - Brincando de telefone/copiando o nome}

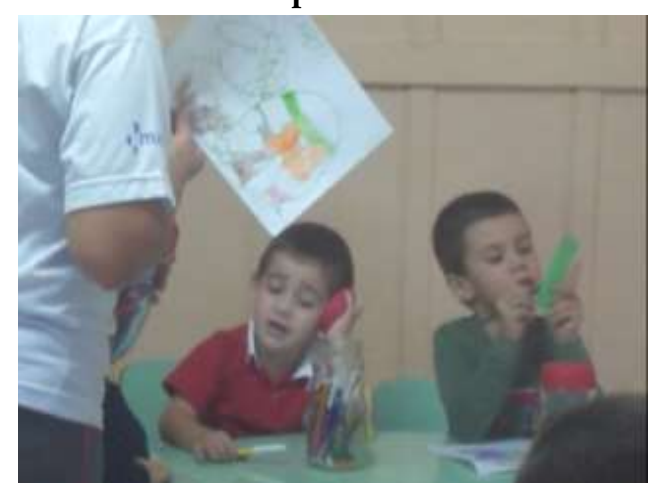

Fonte: Löffler, 2012. 
Imagem 2 - Todos já concluíram...

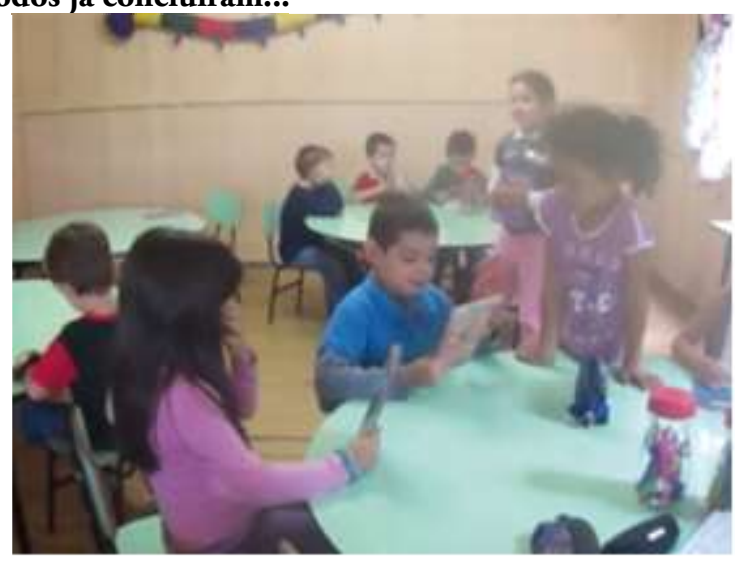

Fonte: Löffler, 2012.

\section{Imagem 3 - Ao fundo, a professora finaliza o trabalho para a criança}

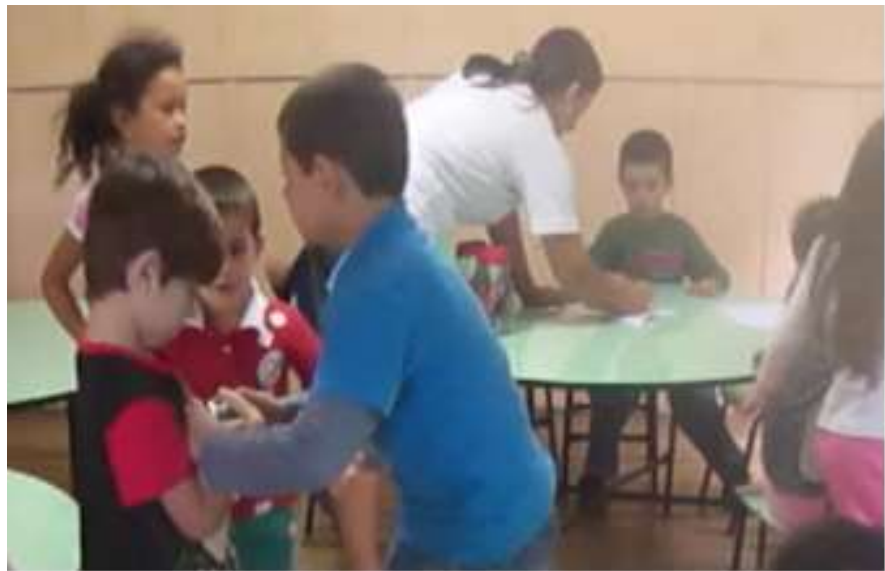

Fonte: Löffler, 2012.

Precisamos pensar, primeiramente, que essas crianças chegaram à escola a partir dos quatro anos e estão, portanto, em início de sua vivência escolar formal. Deparam-se, na chegada, com um ambiente preparado para incentiválas a frequentar a escola, o qual está repleto de cartazes feitos pelas professoras e propostos para quem já é capaz de decodificar as palavras e as informaçóes. As paredes expóem imagens que são relativamente familiares às crianças, visto serem personagens de histórias e de publicidade veiculadas pela televisão, mas 
acompanhados de chamadas escritas com recados, informaçóes ou notícias para os adultos e para os pequenos estudantes sobre regras de conduta no espaço escolar. A eles é informado o grande motivo do seu ingresso na escola: aprender aquilo que ainda não sabem, ou seja, ler e escrever.

É também como se as crianças tivessem que ter, obrigatoriamente, familiaridade com o mundo letrado que é próprio da escola; é como se a escola recebesse todas as crianças como se estivessem retornando de suas férias e todas estivessem lembrando o tempo da leitura e da escrita. Para Arendt (1992, p. 239), essa falta de familiaridade das crianças com o mundo que as recebe é própria da infância, e nele devem ser introduzidas aos poucos, porque "na medida em que ela [a criança] é nova, deve-se cuidar para que essa coisa nova chegue à fruição em relação ao mundo como ele é". Assim, o mundo da escrita é apresentado à criança pré-escolar por uma representação visual com um significado restrito para a maioria delas: o significado do mundo pela versão escolar da leitura e da escrita.

De certo modo, podemos pensar que tais práticas próprias da escola colocam os "pequenos" em contato com a escrita; afinal, este é o lugar privilegiado para sua produçáo e circulação. No Brasil, e em especial nas escolas da zona rural, a presença da língua escrita é ainda mais significativa dada à dura realidade da grande maioria das crianças que frequentam instituições públicas de educação e, em muitos casos, ali encontram a única oportunidade de obter informaçóes que há muito circulam entre as famílias mais escolarizadas (AUGUSTO, 2009). Mas e as práticas sociais? E as produções culturais que são próprias da infância, qual seu lugar nesta escola? Será esse o melhor caminho para apresentar a nossa língua escrita para as crianças menores de seis anos?

A área da educação infantil acumula conhecimento que nos incentiva a pensar que as características específicas do atendimento educacional na infância precisa considerar este duplo desafio: dialogar com os jovens e adultos em formaçáo sobre o mundo, transmitindo nossa experiência já adquirida e, ao mesmo tempo, desafiar os adultos docentes a assumirem este compromisso com o mundo no sentido de que, "face à criança, é como se ele [o professor] fosse um representante de todos os habitantes adultos, apontando os detalhes e dizendo à criança: 'Isto é o nosso mundo!'” (ARENDT, 1992, p. 239).

Nesse sentido, Kishimoto (2013) faz referência à importância da presença da cultura material e imaterial proveniente da cultura popular de cada família, o que se expressa através da escolha, por exemplo, de objetos que sejam 
significativos para as crianças. Há uma consonância entre os pesquisadores da área da educaçáo infantil de que o contexto deve permitir a emergência do letramento, que de acordo com a autora, está relacionado com as açóes de ensinar e aprender as práticas sociais de leitura e escrita (KISHIMOTO, 2010). A questấo trazida para a reflexão está nos critérios de escolha dos elementos que estáo compondo os contextos educativos da infância, se eles sáo significativos e para quem - para as crianças ou para os adultos. A autora destaca que:

Alguns ambientes podem ser ricos em textos impressos
para alguns grupos e pobres para outros, que não veem
a si nem as suas práticas de letramento aí referidas. Para
envolver as crianças, é preciso descobrir os saberes da
cultura popular trazidos de casa. [...] A prática de ignorar
a cultura popular da criança deixa de lado um rico acervo
para dar sequencia ao letramento da casa para a escola. A
desconstruçấo dessa percepçáo propiciaria o letramento
critico e o aproveitamento dos interesses das crianças e
da cultura popular, para, posteriormente, ampliar suas
experiências. (KISHIMOTO, 2013, p. 31-32).

No caso da situaçâo descrita, foi considerado mais importante realizar as tarefas de correspondências entre letras/palavra e o reconhecimento do nome de um modo limitado à conclusão da tarefa do que explorar, por exemplo, a brincadeira de telefonar (simbolicamente realizada com uma tampa). A brincadeira simbólica no contexto da educação infantil também propicia a criação e a expressão oral da criança, e a tradução de uma prática social e seus códigos envolvidos no "falar ao telefone" constituem-se em elementos do letramento, tais como: a estrutura do diálogo, a correspondência entre quem fala e quem responde, o intervalo entre as falas dos comunicantes, os silêncios entre o pensamento e a interlocuçáo, o interlocutor imaginário que ocupa o pensamento e as palavras a serem "escolhidas" para a fala. Linguagem exterior interiorizada?

Tais elementos, se oportunizados como vivência lúdica no contexto coletivo institucional da infância, ampliam a experiência infantil trazida do ambiente familiar, pois à medida que a criança brinca de telefonar está transpondo e ressignificando o uso social da oralidade em sua funçáo de comunicação. Ao brincar de falar ao telefone, as crianças estáo vivenciando a oralidade por meio de uma prática social na qual assume o sistema complexo 
e não como mera base para transposição e decodificação. Por que não explorar mais estas representaçōes das crianças? E, a partir do que argumenta Kishimoto (2013), por que não explorar também a língua escrita como ricos saberes da cultura trazidos de casa?

Diante de tais colocaçóes discutimos as experiências das duas turmas de pré-escola nas quais a diferença de níveis de apropriação de elementos da cultura da escrita entre as crianças (pré-escola urbana) reside exatamente na oportunidade de partilhar os saberes da cultura popular trazidos de casa (KISHIMOTO, 2013). Porém, tomados em sua negatividade, transformam a diferença de práticas sociais de letramento e de vivências existentes entre as crianças em desvantagens diante das tarefas escolares. Uma das principais questôes implicadas nesse processo de apropriação e de desenvolvimento da competência de ler e escrever é que as crianças em idade pré-escolar são tratadas de um modo que pouco faz em nome de suas experiências, suas vivências anteriores à pré-escola, suas impressões, observações e sentimentos. Em outras palavras, a historia pré-escolar dessas crianças é pouco explorada nas práticas educativas institucionais. Se a primeira professora instituiu um processo de ouvir as crianças, o que é extremamente relevante no contexto da Educaçáo Infantil, a segunda sequer considerou que as crianças moradoras de regióes rurais, mas não isoladas, tinham vivências distintas em relação ao ambiente daquelas crianças que ela conhecia de sua experiência docente, mesmo tendo ambas as professoras o código da língua escrita como foco do trabalho.

\section{Quando alfabetizar não pressupõe letrar...}

Os aspectos destacados das duas turmas são diferenciados entre si quanto às posturas das docentes na organização e condução das tarefas das crianças, mas estão sintonizados com o conceito e a perspectiva de antecipação da alfabetizaçáo como uma antecipação da escola do ensino fundamental no que diz respeito à ênfase dada às aprendizagens do sistema de escrita, ou como uma perspectiva alfabetizadora. Conforme o trabalho desenvolvido por Magda Soares (2003) para o grupo de trabalho de alfabetizaçáo da Associação Nacional de Pesquisa em Educação (ANPEd), essas aprendizagens se dão, principalmente, por meio de material produzido artificialmente para "aprender a ler", pois estão embasadas em práticas tradicionais no ensino da língua escrita. A pesquisadora alerta para a progressiva perda de especificidade 
que o processo de alfabetização vem sofrendo na escola brasileira ao longo das duas últimas décadas, ao lado da autonomização de métodos e técnicas de ensino do sistema de escrita, como sendo fatores responsáveis pelo fracasso da aprendizagem e do ensino da língua escrita e a consequente produção de alunos não alfabetizados ou semialfabetizados ${ }^{7}$.

Ao discutir esse conceito de alfabetização, entendemos ser pertinente a posição apresentada por Soares (2003), uma vez que traz à tona não só a evolução conceitual vivida pelos educadores brasileiros, mas também a introdução do conceito de letramento nos modelos de ensino e de aprendizagem da língua escrita. Segundo a autora, enquanto em países como França e Estados Unidos são os problemas de baixa competência em práticas sociais de leitura e escrita que originam, de forma independente, o conceito de letramento,

[...] no Brasil [...] o movimento se deu, de certa forma, em direção contrária: o despertar para a importância e a necessidade de habilidades para o uso competente da leitura e da escrita tem sua origem vinculada à aprendizagem inicial da escrita, desenvolvendo-se basicamente a partir do questionamento do conceito de alfabetização. Assim, ao contrário do que ocorre em países do Primeiro Mundo, como exemplificado com França e Estados Unidos em que a aprendizagem inicial da leitura e da escrita - a alfabetização, para usar a palavra brasileira - mantém sua especificidade, no contexto das discussóes sobre problemas de domínio de habilidades de uso da leitura e da escrita - problemas de letramento - no Brasil os conceitos de alfabetizaçáo e letramento se mesclam, se superpóem, frequentemente se confundem. (SOARES, 2003, p. 3-4)

Entendemos que muitas vezes o que ocorre é a sistematização do processo de ler e escrever independente e antes do trabalho de exploração das diversas formas de representação da linguagem, da qual a escrita é uma forma gráfica da linguagem.

Considerando a discussão proposta por Magda Soares (2003), podemos afirmar que a aprendizagem inicial da tecnologia da escrita na Educação Infantil está ocorrendo de forma independente e apressada, porque está vindo antes 
da aprendizagem das competências de leitura e de escrita necessárias para a participação ativa em práticas sociais de leitura e escrita.

Em outras palavras, o tempo formal de sistematizar as aprendizagens para ler e escrever se dá nos Anos Iniciais do Ensino Fundamental, enquanto que, de acordo com as Diretrizes Curriculares Nacionais para a Educação Infantil (BRASIL, 2009b), as práticas pedagógicas para essa etapa da Educação Básica devem ter como eixos norteadores as brincadeiras e as interaçóes, assegurando experiências de conhecimento de si e do mundo, imersão nas diferentes linguagens $\mathrm{e}$, principalmente, que possibilitem às crianças experiências de narrativas, de apreciação e interação com a linguagem oral e escrita, e convívio com diferentes suportes e gêneros textuais orais e escritos, partindo do contexto de vida da criança e ampliando, gradativamente, seu repertório de experiências. É nessa perspectiva que afirmamos a diferença entre a sistematizaçâo da língua escrita como atividade de ensino nos Anos Iniciais e a sua sistematização como vivências variadas de contato com a linguagem, enquanto uma atividade criadora e constitutiva de conhecimento e, por isso mesmo, transformadora (SMOLKA, 1989).

No quadro 2 trazemos a descrição de outra cena registrada em diário de campo que representa as discussóes acima apresentadas.

\section{Quadro 2 - Excerto do Diário de Campo}

[...] As crianças estavam finalizando uma tarefa do dia anterior que consistia em pintar os desenhos, recortar as palavras e colar abaixo do referido desenho. Uma das crianças veio até mim e disse "Eu já sei soletrar 'bala', quer ver?", eu disse que sim e ele continuou "Bala é B, A, L e A. E eu também sei bola, que é B, O, L e A". Perguntei então se ele saberia soletrar 'boca', me disse que não; então tentei outra, 'dedo', e ele também não soube soletrar. Observei nas tarefas já realizadas e expostas na parede e nesta que as crianças estavam concluindo que havia figuras das palavras soletradas por esta criança. [...].

Diário de campo, 09/11/2012.

Fonte: Löffler, 2012.

A situação descrita no quadro 2 desafia-nos a pensar o quão significativas estão sendo estas práticas de escrita e de leitura para as crianças. As açóes pedagógicas estão priorizando o ensino das famílias silábicas em detrimento de momentos de brincadeiras de faz de conta ou de construçóes com diferentes 
materiais, além de estarem pautadas numa perspectiva de reprodução de modelos desconexos com as vivências infantis. Não que as crianças ignorem esses materiais, ou que eles não devam fazer parte do repertório de conhecimento social das crianças, mas tais práticas constituem uma experiência escolar cujo sentido se restringe ao que Vygotsky (1994, p. 139) já apontava no trabalho sobre "A pré-história da linguagem escrita", destacando o "ensino" da linguagem escrita:

[...] até agora, a escrita ocupou um lugar muito estreito na prática escolar, em relação ao papel fundamental que ela desempenha no desenvolvimento cultural da criança. Ensina-se as crianças a desenhar letras e construir palavras com elas, mas náo se ensina a linguagem escrita. Enfatiza-se de tal forma a mecânica do ler o que está escrito que acaba-se obscurecendo a linguagem escrita como tal.

Nosso entendimento desse processo é de que quando as professoras assumem a perspectiva do ensino tradicional e formal do Ensino Fundamental na pré-escola, elas se enfileiram na homogeneização das práticas educativas da Educação Básica em geral, pois evitam trazer para o currículo da educação infantil as experiências extraescolares das crianças. Essa perspectiva educativa evita o tratamento da criança como sujeito social, histórico e culturalmente constituído como alguém que não só está no mundo em interação com diferentes contextos, mas que também já é portadora de conhecimentos a respeito do mundo que a envolve, produzindo entendimentos e tentando atribuir significados e sentidos para os fatos, para os objetos e para as açóes deste mundo. Reafirmar isso é confirmar a condição da criança como ser singular.

Trazemos também dois exemplos de tarefas de pré-alfabetização apresentadas às crianças na pré-escola rural:

- Tarefa 1: Ajude o Zequinha a pescar sílabas escrevendo palavras dentro dos peixinhos (Imagem 4). E as palavras a serem "pescadas" estão escritas ao final da página, abaixo do desenho: dedinho, bebida, balāo, bigode, bule, boneca, cocada, cabide, bola, bicada. (Folha avulsa fotocopiada sem referência à obra/livro didático da qual fora retirada, e entregue individualmente às crianças). 
Imagem 4 - Tarefa 1

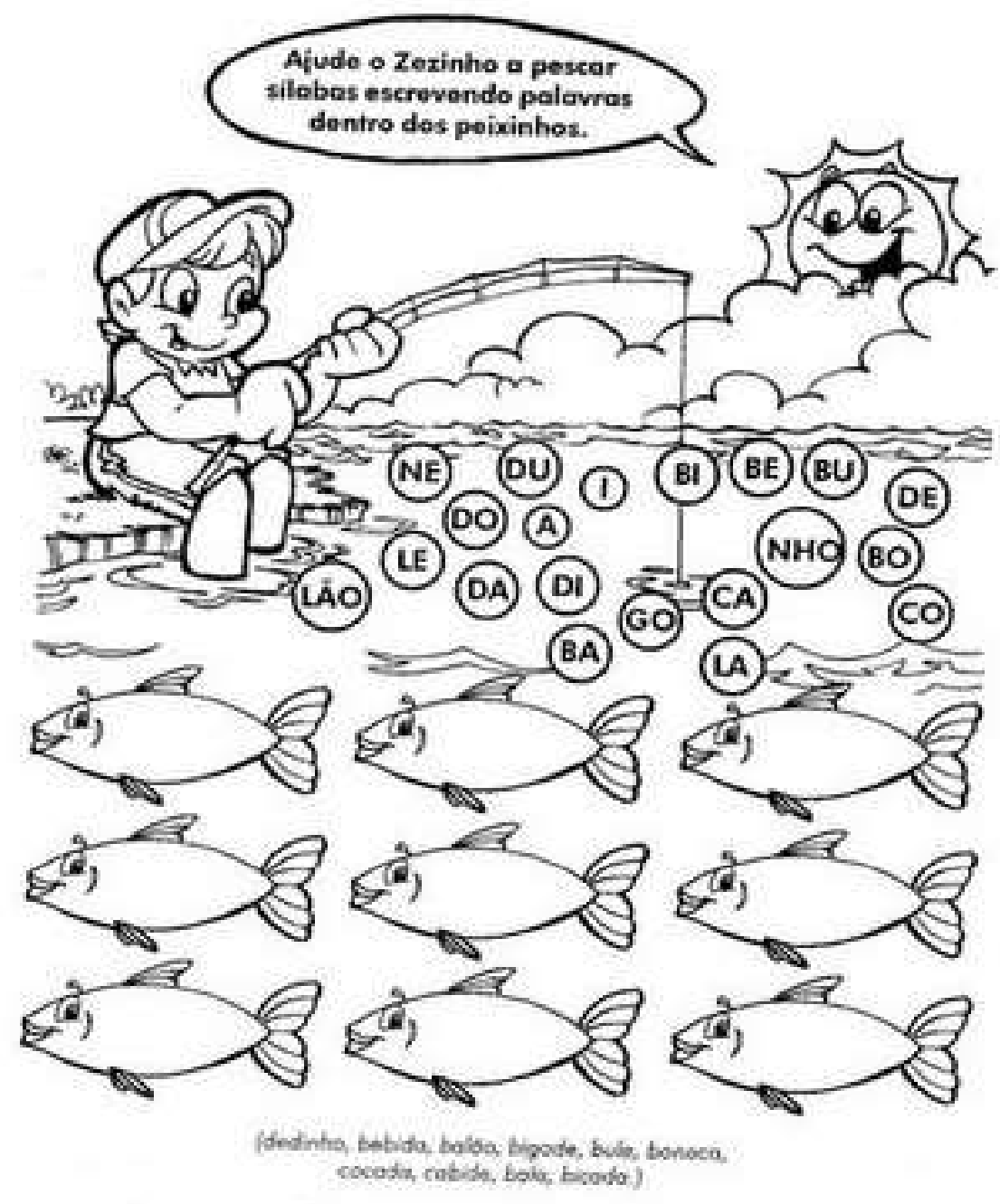

- Tarefa 2: Recorte e cole (Imagem 5). A tarefa proposta deve ser concluída recortando as palavras listadas separadamente abaixo dos desenhos e colá-las no retângulo vazio embaixo das respectivas imagens/desenhos correspondentes. (Folha avulsa fotocopiada sem referência à obra/livro didático da qual fora retirada, e entregue individualmente às crianças). 
Imagem 5 - Tarefa 2

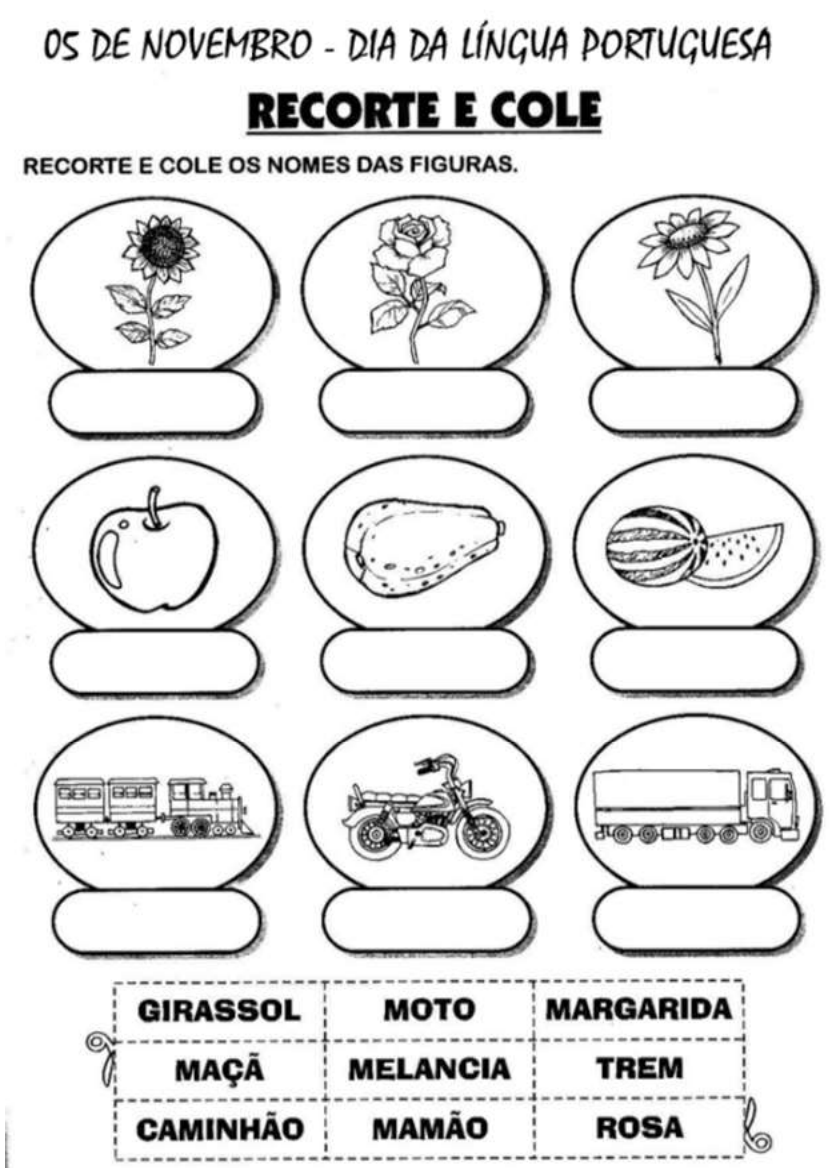

Reafirmamos que a linguagem escrita é diferente de desenhar letras e construir palavras. Isso porque desenhar letras e formar palavras configurase como o que comumente se denomina "escrita mecânica", reduzindo a aquisição da linguagem escrita à aquisição de uma habilidade motora, conforme exposto nos exemplos anteriores. A linguagem escrita vai lém disso: ela é composta por um sistema de signos cuja dominação é um ponto crítico no desenvolvimento da criança, "é um sistema de signos que designam sons e as palavras da linguagem falada, os quais por sua vez, são signos das relaçóes e entidades gerais" (VYGOTSKY, 1994, p. 126). A leitura e a escrita são 
uma atividade cultural complexa e sua aquisição não deve ser mecânica, mas significativa para a criança.

Aprender a ler e a escrever enquanto uma habilidade motora é diferente do que ler e escrever enquanto uma atividade cultural complexa. Para Vygotsky (2009), a leitura e a escrita precisam tornar-se necessárias à criança para que ela possa apropriar-se significativamente deste processo, pois para as crianças pequenas, num primeiro momento, a oralidade é suficiente para comunicar-se, e antes de aprender códigos escritos, a criança precisa entender porque estes códigos são necessários. Como isso acontece no contexto da Educação Infantil?

Existe um fato básico que demonstra com firmeza que, antes da criação literária, a criança deve crescer. Somente num estágio bem superior de acúmulo de experiência, somente num estágio superior de domínio da fala, somente num estágio superior de desenvolvimento do mundo pessoal e interno da criança, torna-se acessível a criação literária (VYGOTSKY, 2009, p. 63).

As colocações de Vygostky (2009) se dão no sentido de que não há como referir à leitura e à escrita na educaçáo infantil sem antes abordar o brincar e o desenhar. A brincadeira, enquanto atividade principal da criança em idade pré-escolar, e o desenho, enquanto uma forma de representação do mundo são elementos que precisam permear as ações docentes na Educação Infantil. Não estamos, contudo, falando de qualquer brincadeira e de qualquer desenho, mas de práticas qualificadas que sejam planejadas e propostas a partir das diferenças entre os interesses e as vivências das crianças, e desenvolvidas em ambientes variados com diversidade de material. Isso porque, em nosso entendimento, contar uma história e pedir que a criança desenhe o que ela entendeu, ou fornecer um desenho pronto da personagem principal para que esse seja colorido ou enfeitado com bolinhas de papel crepom, por exemplo, torna-se uma ação restritiva e limitada se pensarmos em maneiras diversificadas de explorar a história e na capacidade criadora das crianças. Desafiar as crianças a recontála inserindo novos elementos ou a representá-la através da dramatização, ou ainda oferecendo elementos para construçóes de esculturas e maquetes a partir da história, são exemplos de como podemos ampliar e reelaborar nossas açóes docentes ampliando, também, as possibilidades das crianças. 
Da mesma maneira ocorre com as brincadeiras. Brincar todos os dias, com os mesmos elementos, nos mesmos lugares, não são ações que potencializam o desenvolvimento das crianças. Já a proposição de espaços e elementos variados como a reorganização da sala de referência para o grupo, por exemplo, com espaços que permitam a criação infantil são importantes para o desenvolvimento da linguagem em seus conteúdos sociais e de comunicação infantil. Assim, as brincadeiras podem estar integradas com o domínio do simbolismo que, uma vez organizados na dimensão da oralidade, do desenho e da representação em si, a seu tempo, serão sistematizados e expressos pela criança através da linguagem escrita.

As primeiras representações gráficas se dão no sentido das propriedades dos objetos, por exemplo, se as crianças querem desenhar uma mesa, elas desenham um quadrado e náo a mesa em si. Posteriormente, atribuem diferentes sentidos ao mesmo objeto, dependendo do uso que ela faz dele na brincadeira, ou seja, representam os objetos nos seus desenhos e indicam que "a representaçáo simbólica no brinquedo é, essencialmente, uma forma particular de linguagem num estágio precoce, atividade essa que leva, diretamente, à linguagem escrita" (VYGOTSKY, 1994, p. 74).

Assim, o papel do brincar e do desenho na construçáo da escrita se fazem presentes já nas crianças menores, quando elas compreendem a função representativa de uma construção com brinquedos; e, nas maiores, quando nomeiam suas criações antes mesmo de começar a construi-las, demonstrando a compreensão dos seus registros.

O desenho começa quando a linguagem falada já alcançou grande progresso e é habitual na criança, consolidando o processo oral das organizaçôes mentais. Posteriormente, ela estará pronta para registrar essas organizaçóes de outros modos: primeiro com o desenho e depois, com a escrita. A compreensão de que o desenho é uma representação do mundo não apenas limita a simbolização dos objetos, mas também da fala. Compreender que ela também pode ser desenhada é, pedagogicamente, o início da aquisição e desenvolvimento do processo de leitura e escrita. Para isso, existem diferentes métodos, de diferentes abordagens, que estudam a aquisição da linguagem escrita, porém o fundamental é que a passagem ocorra de um modo natural, que seja uma descoberta da criança.

Como expusemos antes, escrever é uma decorrência de duas dimensóes que as escolas de Educação Infantil comumente consideram como desconexas 
no desenvolvimento das crianças: brincar e aprender. Portanto, a criança será capaz de compreender e reconhecer os usos da escrita à medida que as atividades principais do estágio da criança pré-escolar - brincar e desenhar - forem compreendidas enquanto processos de aprendizagem amplamente exploradas. Nas situaçóes em que as crianças recebem fichas para copiar o seu nome, o que de um certo modo pode auxiliar no desenvolvimento da escrita, é importante questionar: as dimensóes do brincar e do desenhar foram suficientemente exploradas? Será que a linguagem escrita é algo necessário a estas crianças? As crianças tiveram/têm a oportunidade de elaborar as suas hipóteses sobre a representação do som, do seu nome como referência de identidade sob a forma de representação na escrita?

Em nossos dados de pesquisas, quando a criança contesta a professora dizendo "Mas eu não consigo!", identificamos que a criança não tem as bases necessárias para dar conta da tarefa que lhe é proposta, e que, nesse contexto, a linguagem escrita está limitada a ser uma atividade mecânica, uma tarefa de identificação apenas. Isso porque as crianças não tiveram a oportunidade de criar suas hipóteses sobre a escrita, relacionando as representaçóes sonoras das palavras, das sílabas, das letras, nem de explorar suficientemente as dimensóes do brincar e do desenhar, relacionando as características físicas da palavra (o tamanho, a quantidade de letras, a letra inicial, a letra final, a ordem em que aparece diariamente na chamada), enfim, cada palavra/nome ao seu "dono", pois essas dimensóes não são compreendidas como atividades principais das crianças.

Em um contexto assim a escrita perde a sua função social, ou seja, o fim mesmo para o qual foi criada, pois a prioridade não é o processo de comunicação ou a criação de diferentes formas de expressão e sim, apenas, o desenho de letras (MELLO, 2009). Em decorrência de práticas assim, as crianças até poderão ingressar nos anos iniciais do ensino fundamental sabendo escrever seu nome e algumas palavras, mas lhes faltará saber o sentido e o significado do código linguístico, o que aponta para escritas limitadas meramente reprodutivas, pois a sua inserção no universo da escrita se deu através de práticas fundamentadas em concepçôes equivocadas e limitadas de alfabetização na Educação Infantil, já que aprenderam que escrever é desenhar letras e não "registrar e expressar informaçōes, ideias e sentidos" (MELLO, 2009, p. 27).

Aprender a ler e a escrever é uma forma de ingressar no mundo adulto e ser parte da sociedade que se comunica de diferentes formas, principalmente pela linguagem escrita. Assim, na Educação Infantil isso deveria significar a 
oportunidade de conhecer a vida através de modos fantásticos, imaginativos e ampliados, sem perder a oportunidade de ser criança no tempo presente da infância, sem ter de deixar de brincar e sonhar para responder a liçôes e demandas de exaustivos trabalhos e estudos.

É preciso afirmar, uma vez mais, que é direito da criança pensar sobre a escrita e praticar sobre ela. E, entendemos como papel da educação infantil, disponibilizar a todas as crianças as informaçóes necessárias para que possam pensar sobre sua própria língua (AUGUSTO, 2009). Entretanto, é preciso sempre afirmar que isso não deve significar, de modo algum, apressar a escolarização, pelo contrário: mais do que preparar para o ingresso no primeiro ano do ensino fundamental, a educação infantil tem que garantir vivências em um currículo

[...] concebido como um conjunto de práticas que buscam articular as experiências e os saberes das crianças com os conhecimentos que fazem parte do patrimônio cultural, artístico, ambiental, científico e tecnológico, de modo a promover o desenvolvimento integral de crianças de 0 a 5 anos de idade. (BRASIL, 2009b, grifo nosso).

As vivências que organizam e propóem o contato com a leitura e a escrita se inserem neste patamar: como conhecimento que faz parte do patrimônio cultural. É muito mais do que meramente memorizar a sequência do alfabeto e do seu nome, ou copiar as ordens das tarefas do quadro para o caderno. $\mathrm{Na}$ Educação Infantil não temos como objetivo garantir que todas as crianças aprendam a ler e a escrever autonomamente, mas como direito político e pedagógico antes afirmado, a vivência com o mundo da escrita assegura a elas o direito de pensar sobre o assunto, de explorar ideias sobre o que se escreve e como se escreve (AUGUSTO, 2009).

\section{Novos (?) desafios para pensar a alfabetização na Educação Infantil}

A discussão que propomos sobre alfabetização para crianças da Educação Infantil, principalmente as de idade pré-escolar, parte do reconhecimento de que o exposto como pano de fundo é a compreensão da complexidade da infância. Ela está indicada pela necessidade de contribuiçóes advindas de 
diversos contextos disciplinares, como, por exemplo, Educação, Psicologia, Antropologia, Sociologia e, sobretudo, porque pressupóe o desafio de dialogar com a dinâmica das realidades sociais, sendo a qualidade e a complexidade das dimensões pautadas nos currículos de formação de professores - em especial no curso de Pedagogia - o desafio mais antigo e, ainda, contundente.

Uma vez que a posição aqui apresentada é por uma oferta de ensino por meio de escolas que não estejam isoladas do meio, entendemos que:

O sistema educacional, através de seus processos didáticopedagógicos, pode ser o tempo e o lugar da mediação destes elementos constitutivos das relaçóes multi/ interculturais, possibilitando hibridismos, mestiçagens, sincretismos inéditos e imprevistos, os quais envolverão conflitos e busca de novos consensos entre grupos e sujeitos que não são semelhantes entre si, mas que, no contato, podem construir momentos e espaços nos quais seja possível a negociação de significados comuns, trocas, abertura à alteridade (ao outro), interaçóes, reciprocidade e solidariedade. (TOMAZZETTI, 2004, p. 66).

Entretanto, a lógica multifacetada das áreas de ensino (as chamadas disciplinas escolares) e a natureza unidimensional com que os currículos e programas são organizados, além de não contemplarem questôes que hoje são prementes para a qualidade na Educação Infantil, também dificultam que avancemos para uma concepção em que a criança seja o foco do projeto educativo. Dito de outro modo, a reificaçáo das concepçôes educativas, em que o foco é o ensino, o produto, a estrutura institucional, é resultado da presença, às vezes invisível, de uma perspectiva homogeneizadora do currículo que imprimiu e imprime referenciais marcadamente padronizadores na formação de professores para a educação da criança. É como se houvesse uma "imagem da alteridade" - no caso da criança -, pré-determinada e padronizada, impedindo que vejamos e atuemos pedagogicamente a partir da centralidade do foco de todo projeto educativo.

Para esta ordem de propostas educativas, cujas relaçôes estão baseadas quase que exclusivamente na heteronomia, é o professor quem assume a posição de único capaz, de orientador direto e de centro do planejamento e da ação. E isso reduz muito os níveis de participaçáo da criança, inviabiliza a observação 
e o acompanhamento das necessidades infantis (as quais são individuais), e sobrecarrega a gestáo pedagógica, transformando-se em atividades transmissivas.

No conjunto, podemos afirmar que essas características são facilmente identificadas com as práticas tradicionais da educação e que, infelizmente, inspiraram muitas das pedagogias - que, por sua vez, surgiram com a escola elementar ou fundamental, pensada para as crianças maiores! $\mathrm{E}$ as pedagogias da educação infantil, que são aquelas destinadas às crianças menores de seis anos, hoje diferenciadas também entre bebês, crianças pequenininhas e as crianças pré-escolares.

Nesse sentido, os momentos de aprendizagem da leitura e da escrita não precisam ser os momentos mais importantes do início da vida escolar das crianças se entendermos que elas não aguardam, necessariamente, a escola para iniciarem essas aprendizagens. Esse processo ainda pode ser encarado como um acontecimento em que elas aprendam também a ler e a escrever descobrindo os caminhos sem deixar de ser criança.

Exemplo disso são as práticas pedagógicas nas quais o/a professor/a atua como leitor/a das crianças, criando oportunidades para elas desenvolverem a capacidade de ouvir, e também de contar suas histórias, de se fazer entender no grupo, de registrar os seus pensamentos nas mais variadas formas e de imaginar, exercendo assim a sua ação criadora. No texto Leituras com letras e sem letras na Educação Infantil do Norte da Itália, Rizzoli (2009) destaca que ouvir e contar histórias são práticas que devem se iniciar já nos berçários, pois para além da história contada, o importante é estar junto, são as relações de afeto, de partilha e cumplicidade que se estabelecem quando propomos às crianças momentos de encontros.

Isso não significa que ao contarmos uma história todos devem estar imóveis e atentos a ela no mesmo momento, nem que ao final seja cobrado algum trabalho. Mas significa que a história é um elemento da cultura que irá ampliar o repertório das crianças e que através do modo como a realizamos, elas começam a perceber a importância das pausas e das entonaçóes para a compreensão do que está sendo dito; elas podem se colocar como autoras das suas próprias histórias, as quais vão sendo registradas pelo/a professor/a que atua nesse processo como escriba.

Práticas de registro na sala de aula como construção de bilhetes para as famílias, narrativas do cotidiano na escola, além de cartazes e livros com 
registros das observaçóes das crianças, suas opinióes, conceitos e informaçóes significativas para elas, são exemplos de como a/o professor/a, ao atuar como escriba da criança, a insere no universo letrado sem ter como objetivo primeiro a sua alfabetização e a decodificação dos códigos linguísticos. Além disso, brincar com a sonoridade das palavras, com rimas, poemas, parlendas, trava-línguas e ter acesso a variados suportes de texto (embalagens, informativos, revistas etc.) também são elementos que contribuem para inserir a criança nesse universo.

Dito de outro modo, a escola pode organizar atividades que possibilitem à criança pequena viver a experiência da infância não na negatividade de deixar de ser não-leitora, mas na positividade de tornar-se leitora junto com outras crianças e também com os adultos.

Esses adultos precisam, sobretudo, partilhar suas faltas e suas necessidades, pois sair do isolamento profissional em que muitas vezes se colocam como educadores das crianças pré-escolares permite-lhes disponibilizar competências que atuam no sentido de resistir e, até mesmo, romper com a cultura institucional que preconiza currículos escolares em suas versóes estreitas e limitadas da experiência humana como a cultura do nosso tempo.

A criança está inventando sua existência no sentido que Paulo Freire (1996, p. 55) atribui ao inacabamento humano: "o inacabamento do ser ou sua inconclusão é próprio da experiência vital. Onde há vida, há inacabamento [...] através da invenção da existência". Cada criança é, ao mesmo tempo, o novo que se inaugura e o velho que ressurge...

\section{Notas}

${ }^{1}$ As questóes referentes a este caso foram desenvolvidas a partir dos registros de uma estagiária do curso de Pedagogia da UFSM, participante do GIECEI, que desenvolveu seu Estágio Supervisionado nesta turma de pré-escola.

${ }^{2}$ As questôes referentes a estas práticas pedagógicas foram desenvolvidas por LÖFFLER (2013), na Dissertação de Mestrado em Educação cujos dados subsidiaram as reflexôes para este artigo.

${ }^{3}$ Podemos destacar a influência do RCNEI em 42\% das propostas analisadas pela pesquisa em convênio entre Ministério da Educação (MEC/SEB/ COEDI) e a Universidade Federal do Rio Grande do Sul (UFRGS), 2009. 
${ }^{4}$ Usaremos este termo quando estivermos nos referindo às crianças de zero a cinco anos de idade que frequentam as escolas de Educação Infantil.

${ }^{5}$ De acordo com os dados do Instituto Brasileiro de Geografia e Estatística (IBGE), Censo Demográfico de 2010, o município tem aproximadamente 261.031 mil habitantes.

${ }^{6}$ Em 2013, a frequência à pré-escola passou a ser obrigatória a partir dos quatro anos de idade e, segundo dados disponíveis no estudo "Radiografia da Educação Infantil no Rio Grande do Sul”, de 2013 (com dados do Censo Escolar de 2012), nos Municípios entre 100 e 500 mil habitantes, a situação da pré-escola é de apresentar a menor taxa de atendimento do Rio Grande do Sul (55,17\% versus 67,57\% no Estado), e as matrículas na pré-escola se dividem basicamente entre instituiçóes públicas $(28,98 \%)$ e privadas $(24,52 \%)$. Especificamente no município de Santa Maria, são 6.091 crianças de quatro e cinco anos, e dessas, 3.993 estão matriculadas em pré-escolas, ou seja, 65,56\% do total da faixa etária. Informação disponível em:http://www1.tce.rs.gov. $\mathrm{br} /$ portal/page/portal/tcers/publicacoes/estudos/estudos_pesquisas/ Radiografia_Educacao_Infantil2013.pdf>. Acesso em: 29/04/2013.

${ }^{7}$ Aqui podemos citar as crianças que chegam nas últimas turmas dos Anos Iniciais sem saber ler e escrever e as crianças que já no $1^{\circ}$ ano do Ensino Fundamental são alfabetizadas, mas suas histórias orais, por exemplo, sáo limitadas e as possibilidades de movimento corporal e as noçóes de lateralidade e espaço dele decorrente não foram amplamente desenvolvidas, pois suas escritas não respeitam os limites das folhas e linhas.

\section{REFERÊNCIAS}

ARENDT, Hanna. Entre o passado e o futuro. São Paulo: Perspectiva, 1992.

AUGUSTO, Silvana de Oliveira. A linguagem Escrita e as crianças: superando mitos na Educação Infantil. In: EDUCAÇÃO Infantil: diferentes formas de linguagem expressivas e comunicativas. São Paulo: UNESP/ UNIVESP, 2009. p. 120-133. Disponível em: <http://www.acervodigital. unesp.br/bitstream/123456789/452/1/01d14t09.pdf>. Acesso em: 19/08/2013. 
BARBOSA, Maria Carmen Silveira. Práticas cotidianas na Educação Infantil: bases para a reflexão sobre as orientações curriculares. Brasília, DF: MEC/ SEB, 2009. Disponível em: <http://portal.mec.gov.br/dmdocuments/relat_ seb_praticas_cotidianas.pdf $>$. Acesso em: 21/06/2010.

BRASIL. Ministério da Educação e do Desporto. Secretaria de Educação Fundamental. Referencial curricular nacional para a educação infantil / Ministério da Educação e do Desporto, Secretaria de Educação Fundamental. - Brasília: MEC/SEF, 1998.

BRASIL. Ministério da Educação. Secretaria da Educação Básica. Relatório de Pesquisa: mapeamento e análise das propostas pedagógicas municipais para a educaçáo infantil no Brasil. Brasília: MEC/SEB, 2009a. Disponível em: <http://portal.mec.gov.br/dmdocuments/relatmieib_anexo1_2.pdf>. Acesso em: 21/06/2010.

BRASIL. Conselho Nacional de Educação. Câmara de Educação Básica. Resoluçáo no 5, de 17 de dezembro de 2009. Institui as Diretrizes Curriculares Nacionais para a Educação Infantil. Diário Oficial da União, Brasília, DF, 18 dez. 2009b. Disponível em: <http://portal.mec.gov.br/ dmdocuments/rceb005_09.pdf>. Acesso em: 21/06/2010.

FARIA, Ana Lucia Goulart de; MELLO, Suely Amaral (Org.). Linguagens infantis: outras formas de leitura. Campinas, SP: Autores Associados, 2009.

FERREIRO, Emília; TEBEROSKY.Ana. Psicogênese da Lingua Escrita. Porto Alegre, Artes Médicas, 1985.

FLÔRES, Vanessa M. A gestão escolar democrática em interlocução com a qualidade na educação infantil. 2014. 127 f. Dissertação (Mestrado em Educação) - Universidade Federal de Santa Maria, Santa Maria, RS, 2014.

FREIRE, Paulo. Pedagogia da autonomia: saberes necessários à prática educativa. Coleçáo Leitura. Rio de Janeiro, Paz e Terra, 1996.

KISHIMOTO, Tizuko Morchida. Alfabetização e letramento/literacia no contexto da educaçáo infantil: desafios para o ensino, para a pesquisa e para a formaçáo. In: FRADE, Isabel Cristina Alves da Silva et al. Convergências e tensóes no campo da formação e do trabalho docente. Belo Horizonte: Autêntica, 2010. p.134-155. 
KISHIMOTO, Tizuko Morchida. Brincar, letramento e infância. In: KISHIMOTO, Tizuko Morchida; OLIVEIRA-FORMOSINHO, Júlia (Org.). Em busca de uma pedagogia da infância: pertencer e participar. Porto Alegre, RS: Penso, 2013. p. 21 - 53.

LÖFFLER, Daliana. Educaçāo Infantil na Escola do Campo: o que as crianças nos sinalizam sobre este contexto. 2013. 116f. Dissertação (Mestrado em Educação) - Universidade Federal de Santa Maria, Santa Maria, RS, 2013.

MELLO, Suely Amaral. O processo de aquisição da escrita na Educação Infantil: contribuições de Vygotsky. In: FARIA, Ana Lucia Goulart de; MELLO, Suely Amaral (Org.). Linguagens infantis: outras formas de leitura. Campinas, SP: Autores Associados, 2009. p. 21 - 36.

OLIVEIRA-FORMOSINHO, Júlia (Org.). Modelos curriculares para a Educação de Infância: construindo uma práxis de participação. Porto, PT: Porto Editora, 2009. (Coleção Infância).

RIZZOLI, Maria Cristina. Literatura com letras e sem letras na educação Infantil do Norte da Itália. In: FARIA, Ana Lucia Goulart de; MELLO, Suely Amaral (Org.). Linguagens infantis: outras formas de leitura. Campinas, SP: Autores Associados, 2009. p. 5 - 19.

SMOLKA, Ana Luiza B. A atividade da leitura e o desenvolvimento das crianças. In: SMOLKA, Ana Luiza B. et al. Leitura e desenvolvimento da linguagem. Porto Alegre: Mercado Aberto, 1989. p.23-41.

SOARES, Magda. Letramento e alfabetização: as muitas facetas. In: REUNIÃO ANUAL DA ASSOCIAÇÃO NACIONAL DE PESQUISA EM EDUCAÇÃO, 26., 2003, Poços de caldas. Anais... Rio de janeiro: ANPED, 2003.

TOMAZZETTI, Cleonice Maria. Pedagogia em infância na perspectiva intercultural: implicaçóes para a formação de professores. 2004. 241f. Tese (Doutorado em Educação) - Universidade Federal de Santa Catarina, Florianópolis, 2004.

VYGOTSKY. Lev Seminovich. A Formação Social da Mente. São Paulo: Martins Fontes, 1994.

VYGOTSKY. Lev Seminovich. Imaginação e criação na infância: ensaio sociológico. Tradução de Zóia Prestes. São Paulo: Ática, 2009. 


\section{El sentido de alfabetizar en el nivel inicial: algunas reflexiones}

\section{Resumen}

El presente texto es resultado del análisis de datos producidos a partir de trabajos circunscriptos al nivel inicial (preescolar) desarrollados con dos maestras en momentos y contextos distintos. Las fuentes de producción y de análisis de los datos fueron obtenidas, principalmente, de los registros desarrollados durante la práctica de residencia en la Educación Infantil y durante la investigación de la maestría en educación. A partir de los registros proponemos algunas reflexiones en relación al proceso de apropiación de la lengua escrita por parte de los niños y niñas en la edad pre-escolar, como también son exploradas las dimensiones de infancia institucionalizada, creación, participación y generación de nuevas potenciales que se entrecruzan con dimensiones propuestas en las acciones docentes, como por ejemplo, control y repetición. Cuestionamos los sentidos de las prácticas "alfabetizadoras" en contrapunto a la lectura del mundo que los niños y niñas hacen, sueñan y viven el potencial de la existencia humana. Tales reflexiones sobre los sentidos de alfabetizar en la pre-escuela son desarrolladas a la luz de las Directrices Curriculares Nacionales para la Educación Infantil, Brasil y de referencias propias del área de alfabetización. Las discusiones presentadas en el presente texto consideran que la complejidad de

\section{The meanings of literacy in pre-school: some reflections}

\section{Abstract}

This text is the result of data analysis produced in circumscribed work at pre-school level, developed with two teachers in different time and contexts. The production and data analysis sources for this text were obtained mainly from the stage of supervised practice records in kindergarten and from the master research in education. From these records we propose some reflections about the language appropriation process written by children of preschool age and we explore aspects of institutionalized childhood, creation, participation and generation of new potentials that cross each other with dimensions proposed in teaching actions, such as control and repetition. This paper questions the meanings of "literacy teachers" practices as opposed to the world reading with children who do, dream and live the power of human existence. Such reflections on the meanings of literacy in preschool are developed in the light of the National Curriculum Guidelines for Early Childhood Education and own references of literacy area. The discussions presented in this text consider the complexity of childhood allows us to understand the children in immersion in reading and writing universe long before attending schools, facing this moment as not exclusive to the beginning of children school life. This process can be seen as an initiation or event, where children 
la infancia nos permite comprender a los niños ya inmersos en la lectura y la escritura mucho antes de ir a la escuela, enfrentado este momento como algo no exclusivo del inicio de la vida escolar. Este proceso puede ser entendido como una iniciación o acontecimiento, en que los niños también aprenden a leer y a escribir descubriendo caminos sin dejar de ser niños, pues ellos no aguardan, necesariamente, la escuela para iniciar esos aprendizajes.

Palabras claves: Alfabetización. Literacia. Educación preescolar. also learn to read and write discovering the paths while remaining child, as they await not necessarily the school to take up such learning.

Keywords: Literacy. Literacy. Pre-school education.

\section{Cleonice Maria Tomazzetti \\ E-mail:netcleo@gmail.com}

\section{Daliana Loffler}

E-mail: dalianaufsm@yahoo.com.br

Enviado em: $30 / 8 / 2014$

Aprovado em: 2/12/2014 